\title{
COMPARATIVE STUDY OF BAR, POSITIONER AND BALL ATTACHMENT IN SOLITARY VERSUS SPLINTED IMPLANT ASSISTED MANDIBULAR OVERDENTURE (IN VITRO STUDY)
}

\author{
Mohamed H EL-Ebiary ${ }^{1 *} b d s$, Lubna M Eldidi ${ }^{2}$ phd, Ahmed A Abdelhakim ${ }^{3}$ hh.
}

\begin{abstract}
INTRODUCTION: Complete denture is the standard treatment for entirely edentulous patients. However, patients may have major problems using their traditional complete dentures due to lack of retention, support and stability and the associated chewing capacity compromise. Endosseous implants proved a successful therapy for these patients. Different overdenture attachment systems could be used for mandibular implant overdentures to improve denture retention and stability.

AIM OF THE STUDY: this study aimed to study the retention of the prosthesis with different implant number and different attachment systems.

MATERIALS AND METHODS: The model was used in two groups according to the number of implants. Group A model with two loaded implants in the canine area. Group B model with four loaded implants in the canine area and in the second premolar area. Each group was divided into three sub-groups with different attachment systems positioner, bar \& ball. Retention of attachments was tested by universal testing machine.

RESULTS: It was observed that there was statistically significant difference between the different attachment systems, as bar attachment showed higher retentive force value with mean $=101.47 \pm 25.04$ compared with locator attachment with mean $=55.53 \pm 15.98$ and ball

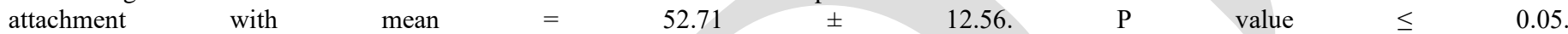
CONCLUSIONS: bar attachment group showed favourable retentive force compared with locator and ball attachment, and four implants overdenture showed higher retentive force compared with two implants overdenture.
\end{abstract}

KEYWORDS: Implant overdenture, Bar attachment, Ball attachment, Locator attachment.

1. Instructor of prosthodontics, faculty of dentistry, Alexandria University

2. Lecturer of prosthodontics, faculty of dentistry, Alexandria University

3. Professor of Prosthodontics, Faculty of Dentistry, Alexandria University
* Corresponding author

E-mail: ebiary1@gmail.com

\section{INTRODUCTION}

Edentulism, according to the Glossary of Prosthodontic Terms, is defined as the state of being without any natural permanent teeth (1).

The conventional treatment for completely edentulous patient is complete denture. Edentulous patients may have major difficulties while using their conventional full dentures because of lack of stability, support, and retention also because the related chewing capacity compromised. Endosseous implants had already proven useful for rehabilitation for completely edentulous patients. A mandibular implant overdenture was seen to enhance chewing function and patient satisfaction in patients with complete denture who choose an implant overdenture alternative (2).

This is agreed that the use of two implant overdenture is not the gold standard for implant therapy, it is the minimum standard that should be appropriate for many people, taking performance, satisfaction of the patient, cost and clinical time into consideration. The use of two implants with an overdenture will give edentulous patients long-term neuromuscular benefits $(3,4)$.

Burns $^{(5)}$ first who tried to answer the question "if a practitioner concludes that a patient would be best treated with an implant overdenture, what percentage implants should be placed?" He found no reply due to lack of adequate data for dealing with this subject

Sadowsky ${ }^{(6)}$ then Suggested many implants for mandibular overdenture where jaw anatomy is sensitive, elevated occlusal forces or high retention requirements are present, or where implant length but $8 \mathrm{~mm}$ or implant width but $3.5 \mathrm{~mm}$ is used

A symposium was held on May 24-25, 2002 at McGill University in Montreal, Quebec, Canada, during which experts presented 15 papers on the efficacy of overdenture for the care of edentulous patients. The consensus was that the overdenture assisted by two implants would become the primary treatment option for the edentulous mandible, While no information concerning the perfect type of attachment was given (7).

A systematic review was presented by Klemetti ${ }^{(8)}$ discussing the following clinical concern: "Is there a certain number of implants needed to retain an overdenture?” in the light of his work, Overdentures with two implants and a bar extension have the least amount of complications in the mandible.

To some degree, the decision on the amount of implants that fits a particular clinical situation is subjective 
and relies on the experience and expertise of the clinician, as well as on several other factors. However, in 2002 and 2009, respectively, two consensus statements about the number of implants to be used with removable implant assisted overdentures were issued. Both statements of consensus suggested that removable implants should be considered as the first-choice standard of treatment for an edentulous mandible $(7,9)$.

Thomason et al (10) aimed to present the existing facts and reasoning in support of the statements of agreement between McGill and York. The result was that there is now sufficient evidence to support the idea that a two-implant overdenture would become the first treatment option for the edentulous mandible. Nevertheless, there was no information provided about the varied choices in the attachment systems, i.e. bar, ball and locator potential adjunctive benefits with the use of additional implants. The included trials were all observations where patients obtained either new full traditional dentures in both the maxilla and mandible or implant assisted mandibular overdenture as opposed to a new traditional maxilla denture.

Different overdenture attachment systems are also used for mandibular implant overdentures to enhance denture durability and stability. Ball, bar, type of magnet, and locator are the most common attachment systems. In general, the option of an attachment system was in line with practitioners ' experience and preferences (2).

A wide range of commercially available attachment systems are used to bind implants to mandibular overdentures, either by splinting the implants or by unsplinting. The anatomical situation of the mandible, desired retention level, hygienic maintenance ability, implant parallelism and considerations of the price are important factors in the selection of the appropriate form of overdenture attachment (11). Splinting systems are suggested in the case of implant angulation differences, while unsplinting systems are typically indicated in clinical circumstances where interarch space is reduced (12).

The most common attachment used for unsplinted implants is that the ball attachment. This attachment system can be a prothetic idea that is effective, practical and comparatively low cost it also has some drawbacks as highprofile design that result in high concentration of stress patterns at the ball's neck transmitting significant quantities of stress to the bone and implant. The other downside of ball attachment is the resin and metal clips can wear easily, thus reducing prosthesis retention $(13,14,15)$.

The bar attachment in contrast allow splinting of implants and improve retention and stability, However, the oral hygiene criteria may have difficulties. The positioner attachment manufactured is a resilient, prefabricated, nonsplinted attachment with a minimum vertical height 3.17 $\mathrm{mm}$ on external hex implants and only $2.5 \mathrm{~mm}$ for a nonhexed internal connection implant which serves as an advantage for cases with small inter-occlusal heightShort profile distance of positioner attachment was found to be beneficial and was related to lowering the load conducted to the implant. It can be demonstrated by that the length of the lever arm, which has a greater mechanical advantage $(16,17,18,19)$.

The positioner attachment design allows the ability to compensate up to $20^{\circ}$ vertical plane implant angulations equal to $40^{\circ}$ divergence between two implants which avoids the need for angled abutment positioning. This mechanism reveals great benefit by doubling the retention area known as "Dual retention" to ensure long-lasting retention $(20,21)$.

The exact number of implants needed to have an acceptable outcome for mandibular implant overdenture care remains questionable. It has been recognized that for many patients the importance of fewer implants as a price saving strategy features a merit. In some cases, however, the use of very two implants is suggested to provide greater overdenture stability and to maintain the supporting periimplant bone (22).

Few research contrasted different attachments in a way that was beneficial to clinical decision taking. This research was therefore performed to determine the durability of the different attachment systems in regarding the number of implants.

\section{MATERIALS AND METHODS}

Mandibular edentulous acrylic model. (Acrostone Dental Manufacture, England)

Dental implants analogs (diameter, $3.6 \mathrm{~mm}$; length, $12 \mathrm{~mm}$ ) (dentium, korea)

Acrylic resin mandibular overdentures fabricated with heat cure PMMA (Acrostone Dental Manufacture, England)

Self cure acrylic resin (Acrostone Dental Manufacture, England)

Prefabricated ball/o-ring attachment (dentium, korea)

Prefabricated positioner/locator attachment (dentium, korea)

Hader bar and clip attachment (Rhien83, Germany)

Universal testing machine.

\section{METHODOLOGY}

Preparation of the model

An edentulous mandibular stone model was replicated into heat-curing acrylic resin without ridge undercuts (Acrostone Dental Manufacture, England) and used all of the experiment (Figure 1). In the canine and second premolar regions of the model four channels were drilled parallel to each other using a dental milling machine (Bredent GmbH \& Co, Senden, Germany). Four spiral threaded dentium (Dentium Superline - Dentium Inc., Seoul, Korea) implants were inserted with torque wrench in the drilled holes.

The model was used in the two groups according to the number of implants loaded. The first group received only two loaded implants in the canine area, while the second group received four loaded implants in the canine area and in the second premolar area.

Group A was subdivided into three subgroups:

I- The two implants loaded in the canine area received two solitary ball attachments

II- The two implants loaded in the canine area received two positioner attachments

III- The two implants loaded in the canine area received a bar attachment with

Only one clip in the fitting surface of the acrylic base.

Group B was subdivided into three subgroups:

I- The four implants received four solitary ball attachments. II- The four implants received four solitary positioner attachments. 
III- The four implants received three bar attachments with three clips in the fitting surface of the overdenture.

\section{Fabrication of the mandibular overdenture}

Maxillary and mandibular trial denture bases with wax occlusion rims were constructed on the duplicated stone model and mounted on mean value articulator. Six mandibular trial denture bases were constructed on the mounted duplicated stone models. The same set size mandibular acrylic teeth (size 22) were arranged on all the trial denture bases with keeping the opposing maxillary trial denture base in place to ensure standardization of all mandibular dentures.

Flasking and packing using heat cure polymethyl methacrylate were performed for the six mandibular trial dentures. Finishing and polishing were done for all the overdentures using conventional methods (Figure 2).

\section{Pick-up of the different attachments}

Each attachment system was screwed to each implant under torque $20 \mathrm{~N}$ using torque wrench. Then white blockout spacer ring was placed around each abutment, then a metallic housing was placed over each abutment and was pressed down to ensure that the abutment engages.

The areas where the caps touch the over denture were relieved using an acrylic bur. The overdenture was placed to ensure that the caps are in no way in contact with the acrylic overdenture.

Throughout the denture, lingual vent openings were made to envision the complete seating and to vent excess material. Self-cure PMMA was mixed and applied in the denture relief areas and then sat over the caps, and stayed until the material was set. The finishing and polishing was performed to acrylic resin.

\section{Retention test}

The experimental overdenture has attached to four $15-\mathrm{cm}-$ long metal wires through metal loops. The end of the wires was connected a $5 \times 5 \mathrm{~cm} 2$ metal plate with four drilled openings at the corners. The wires were balanced to increase or decrease their length by tightening the wires attached to the plate before increasing measurement to reduce slackness (Figure 3).

At the base of the test model, a metal bar projection was built anteroposteriorly around the cast core. This bar was used to fasten the test model to the test machine frame. The model's occlusal plane was mounted, along with the test machine's horizontal plane of the metal base. The machine was balanced and equilibrated using a computer algorithm to compensate for the weight of the experimental overdentures and wires. The testing machine has been used to conduct vertically oriented four-point tensile forces on the metal frame to separate the attachments from the abutments (Figure 4).

The testing machine was set at a fixed $50 \mathrm{~mm} /$ min crosshead speed to simulate the speed of the overdenture motion away from the ridge during action. The maximum loads needed to disengage the overdenture (in $\mathrm{N}$ ) from the test model (retaining force) were measured.

\section{Statistical Analysis:}

Normality was checked using plots and normality tests and the variable showed normal distribution, so means and standard deviations (SD) were calculated. Comparison of the 2 main groups (different numbers of implants) was done using Independent Samples T test, while comparing different attachment systems was done using ANOVA followed by Tuckey post hoc test with adjustment for many comparisons. Significance was set at $\mathrm{P} \leq 0.05$. Analysis of data was done using IBM SPSS statistical software (version 23).

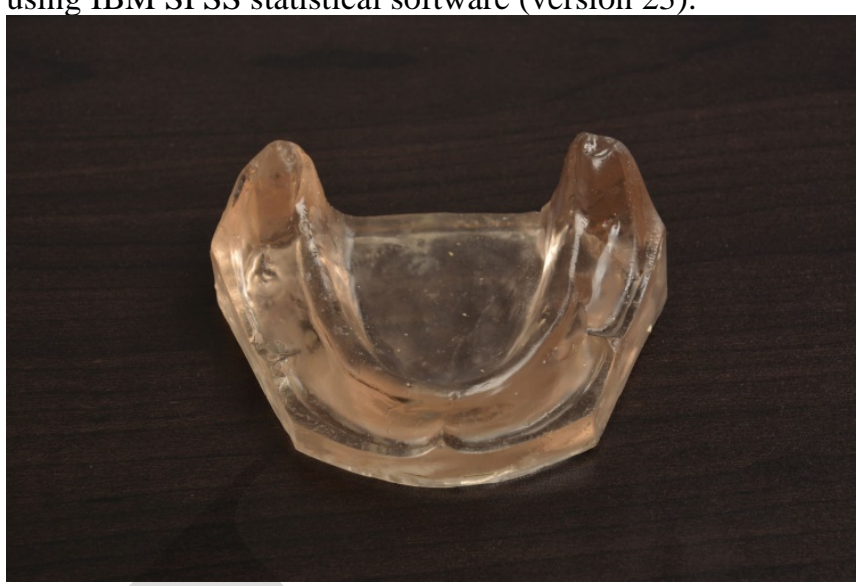

Figure 1: showed an edentulous mandibular heat cured acrylic resin model without ridge undercuts

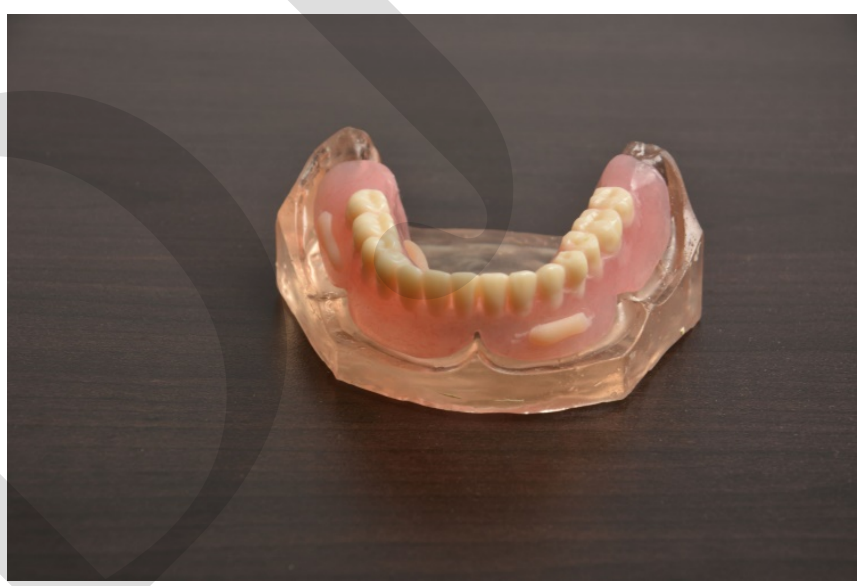

Figure 2: showed mandibular overdenture after finishing and polishing.

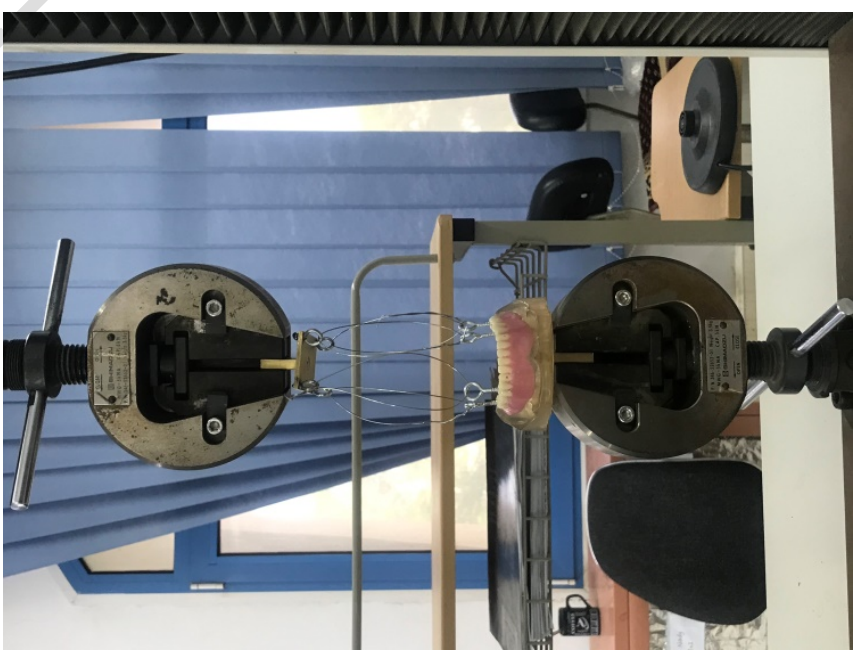

Figure 3: showed Four 15-cm-long metal wires were hooked to metal loops of the experimental overdenture. A $5 \times 5 \mathrm{~cm}^{2}$ metal plate with four tapped holes at the corners was attached to the end of the wires. 


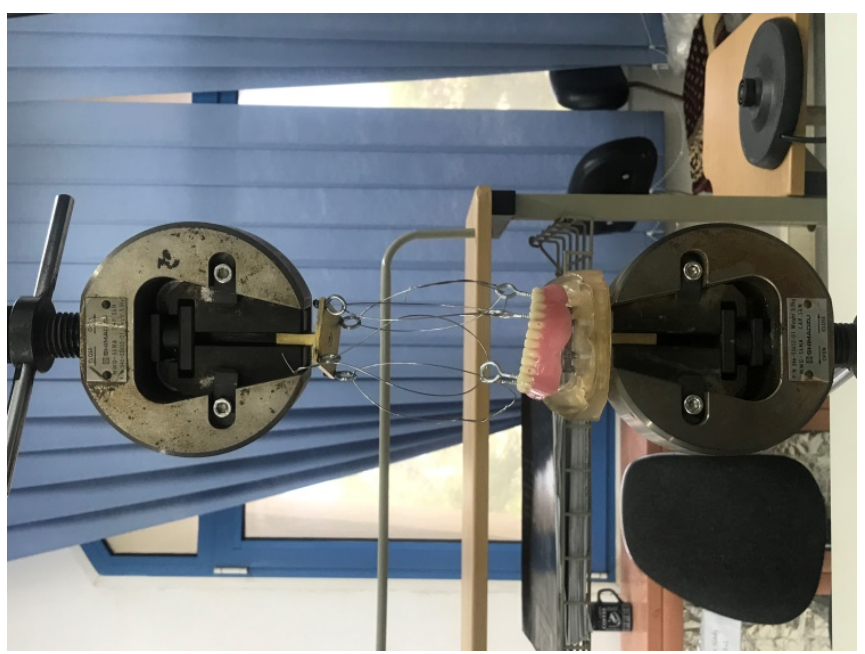

Figure 4: The testing machine was used to apply vertically oriented four-point tensile loads on the metal plate until the attachments separated from the abutments

\section{RESULTS}

This research was conducted to measure the retention of implant assisted mandibular overdenture with various implant numbers using three different attachment designs: ball, locator and bar. Data were collected, tabulated, and statistically presented as follows.

Table 1 showed the comparing values of the Retentive force $(\mathrm{N})$ of the Overdenture with Different implant numbers.

When comparing values of retentive force with different implant numbers, It was observed that there was statistically significant difference between the different implant numbers, as four implants supported overdentures showed higher retentive force value with mean $=86.43 \pm 28.63$ compared with two implants supported overdentures with mean $=53.38 \pm 18.26$. $\mathrm{P}$ value $\leq 0.05$.

Table 2 showed that the comparing values of the Retentive force $(\mathrm{N})$ of the overdenture with various Attachment Systems.

While when comparing values of retentive force with different attachment systems, it was observed that there was statistically significant difference between the different attachment systems, as bar attachment showed higher retentive force value with mean $=101.47 \pm 25.04$ compared with locator attachment with mean $=55.53 \pm 15.98$ and ball attachment with mean $=52.71 \pm 12.56$. P value $\leq 0.05$.

Table 3 showed the comparing values of the Retentive force $(\mathrm{N})$ of the Overdenture with different implant number and different Attachment Systems.

Moreover, It was observed that there was statistically significant difference between the different attachment systems in relation to different implant number, as three bar attachments over four implants showed higher retentive force value with mean $=124.92 \pm 6.92$

It was observed that there was no statistically significant difference in the value of the retentive force between ball attachment and locator attachment.

Table 1: showed the comparing values of the Retentive force $(\mathrm{N})$ of the Overdenture with Different implant numbers.

\begin{tabular}{|l|l|l|}
\hline & $\begin{array}{l}\text { Group A Loading of } \\
\text { 2 Implants }(\mathrm{n}=18)\end{array}$ & $\begin{array}{l}\text { Group B Loading of } \\
\text { 4 Implants }(\mathrm{n}=18)\end{array}$ \\
\hline $\begin{array}{l}\text { Mean } \\
\pm \text { SD }\end{array}$ & $53.38 \pm 18.26$ & $86.43 \pm 28.63$ \\
\hline $\begin{array}{l}\text { T test } \\
\mathrm{P} \\
\text { Value }\end{array}$ & $\begin{array}{l}4.13 \\
<0.001^{*}\end{array}$ \\
\hline
\end{tabular}

*statistically significant at $\mathrm{P}$ value $\leq 0.05$

Table 1: Comparison of the Retention of Overdenture with Different Attachment Systems

\begin{tabular}{|l|l|l|l|}
\hline & $\begin{array}{l}\text { Ball } \\
\text { Attachment } \\
(\mathrm{n}=12)\end{array}$ & $\begin{array}{l}\text { Locator } \\
\text { Attachment } \\
(\mathrm{n}=12)\end{array}$ & $\begin{array}{l}\text { Bar } \\
\text { Attachment } \\
(\mathrm{n}=12)\end{array}$ \\
\hline $\begin{array}{l}\text { Mean } \pm \\
\text { SD }\end{array}$ & $\begin{array}{l}52.71 \\
12.56^{a}\end{array}$ & $\begin{array}{l}55.53 \\
15.98^{a}\end{array}$ & $\begin{array}{l}101.47 \\
25.04^{b}\end{array}$ \\
\hline $\begin{array}{l}\text { F } \\
\text { "ANOVA" } \\
\text { P Value }\end{array}$ & 25.93 \\
\hline
\end{tabular}

*statistically significant at $\mathrm{P}$ value $\leq 0.05$.

$\boldsymbol{a}, \boldsymbol{b}$ different letters denote statistically significant difference between groups using Tuckey post-hoc test.

Table 3: Comparison of Retention of Overdenture with Different Implant Numbers and Different Attachment Systems

\begin{tabular}{|c|c|c|c|c|c|}
\hline $\begin{array}{l}\text { Group } \\
\text { A with } \\
\text { Ball } \\
\text { Attach } \\
\text { ment } \\
(n=6)\end{array}$ & $\begin{array}{l}\text { Group } \\
\text { A with } \\
\text { Locato } \\
\text { r } \\
\text { Attach } \\
\text { ment } \\
(n=6)\end{array}$ & $\begin{array}{l}\text { Group } \\
\text { A with } \\
\text { Bar } \\
\text { Attach } \\
\text { ment } \\
(n=6)\end{array}$ & $\begin{array}{l}\text { Group } \\
\text { B with } \\
\text { Ball } \\
\text { Attach } \\
\text { ment } \\
(n=6)\end{array}$ & $\begin{array}{l}\text { Group } \\
\text { B with } \\
\text { Locato } \\
\text { r } \\
\text { Attach } \\
\text { ment } \\
(n=6)\end{array}$ & $\begin{array}{l}\text { Group } \\
\text { B with } \\
\text { Bar } \\
\text { Attach } \\
\text { ment } \\
(n=6)\end{array}$ \\
\hline $\begin{array}{l}41.56 \\
\pm 4.40\end{array}$ & $\begin{array}{l}40.57 \\
\pm 2.94 \\
a\end{array}$ & $\begin{array}{l}78.02 \\
\pm \quad 3.47 \\
b\end{array}$ & $\begin{array}{l}63.86 \\
\pm 5.43 \\
c\end{array}$ & $\begin{array}{l}70.49 \\
\pm \quad 3.96 \\
b, c\end{array}$ & $\begin{array}{l}124.92 \\
\pm 6.92 \\
d\end{array}$ \\
\hline \multicolumn{6}{|c|}{$\begin{array}{l}\text { F of ANOVA }=258.80 \\
P \text { Value }<0.001^{*}\end{array}$} \\
\hline
\end{tabular}

*statistically significant at $\mathrm{P}$ value $\leq 0.05$.

$\boldsymbol{a}, \boldsymbol{b}, \boldsymbol{c}, \boldsymbol{d}$ different letters denote statistically significant difference between groups using Tuckey post-hoc test.

\section{DISCUSSION}

The underlying idea of using retentive implant-overdenture systems for the care of edentulous patients is to improve the retention and stability of the dentures, thus promoting chewing ability and patient satisfaction and compliance $(23,24)$.

Locator form, ball, and conventional bar attachments are the widely used anchorage systems in implant-supported overdentures and have empirical evidence for their effectiveness. Those attachment systems were also chosen for this analysis $(25,26)$.

The present in vitro study was aimed to investigate the effect of using ball, locator and bar attachments and compare the retention measurement of implant assisted mandibular overdenture. 
A mandibular completely edentulous silicone mould was used to form mandibular stone cast and a mandibular acrylic resin model (Acrostone Dental Manufacture, England). Heat cure acrylic resin was selected to be used for installation of implants as appropriate elastic modulus for bone analog material was recorded. It was also easy to machine and was strong enough for cyclic testing (27).

The upper and lower stone casts were placed on a mean value articulator and acrylic teeth were arranged. The maxillary record base was kept on the articulator while the six mandibular record bases were interchanged on thje same mounting to preserve the same maxillo-mandibular relation during arrangement of mandibular acrylic teeth to ensure standardization of all the mandibular overdentures. The mandibular canines were arranged to be $22 \mathrm{~mm}$ apart (11 mm from the midline) which simulate the distance between two natural canines (28).

Each implant was $12 \mathrm{~mm}$ long and $3.6 \mathrm{~mm}$ in diameter. The $12 \mathrm{~mm}$ length was chosen as it is considered as an adequate length to obtain optimum stress distribution around the implants (29).

To test the retention force of the overdentures under analysis, the model was fastened to the base of the universal testing machine using the $90^{\circ}$ custom made jig Allowing the application of the tensile force perpendicular to the occlusal plane as much as possible to simulate axially directed dislodging forces when denture is in function. The cross head spead of the universal testing machine was set at 50 $\mathrm{mm} / \mathrm{min}(30,31)$.

In this study, It has been found that statistically significant variations exist between the different implant numbers, as four implants supported overdentures showed higher retentive force value compared with two implants supported overdentures. This result was in line with Scherer M, McGlumphy E, Seghi R, Campagni W, An experiment was carried out using four different types of commercially available attachments, used sequentially in different locations on the model to test the effects of retention and stability of overdentures based on implant number and distribution (31). Sadig W also established that the 2-implant design provides less retention and stability than in the four implant model. Number of implants and type of attachments significantly impacted the retention and stability of overdentures assisted by implants (14). Abdulamajeed A, H.Hassan R founded that stability and retention of implant supported overdenture is greatly impacted by implant number and position as the number of implant increase retention and stability of implant supported overdenture have increased (33). Elmowafy DA, Emera RMK, Hegazy SA founded that while both 2 implants and 3 implants supported mandibular overdenture with attachments to OT Equator gave the same clinical result. The three-implants retained mandibular overdenture gave superior retention forces (34).

However many studies founded that there were no major variations between the 2 and 4 overdentures assisted by implants. Meijer et al. reported the ten year information from Batenburg et al.'s previously published paper and reported that there was no significant correlation between patients presented with a mandibular overdenture of two or four implants with respect to soft tissue clinical condition, radiographic bone loss, patient outcomes and surgical and prosthetic follow up care. A two-implant overdenture has been recommended for reasons of cost-effectiveness $(35,36)$. This variation may be due to the fact that patient satisfaction is dependent on them.

Results of this study have also shown that statistically significant difference exists between the different attachment systems, as the bar attachment had a higher retaining force value compared with ball and locator attachments. They do have a few drawbacks though; they are initially more costly, hard to fix, and it seems difficult to maintain oral hygiene, particularly for weak elderly people. Ball anchors were favored by clinicians compared to the bar attachments because they were less sensitive, expenseeffective, easy to use and to fix $(16,37)$.

However many studies founded that locator attachment showed higher retentive force value compared with bar attachment. Elsayed EL founded that Locator attachments are preferred to sustain overdentures across Dolder bar attachments, because Locator attachments were based on high retention and stability after wearing simulation with limited retention loss. Only the retention and stability of transparent and pink Locator plugs (14.24-43.66 $\mathrm{N})$ following wear simulation were still above the minimum possible retention $(10-20 \mathrm{~N})$ required to reach good patient comfort (38).

This finding is similar to Burns et al. In the anterior mandible thirty specimens were given four implants. Three various types of overdenture attachments were produced for each subject and/or attached to the implants: bar attachments over four implants, two ball attachments and bar attachments over two implants. Those subjects provided all three forms of attachments for around 1 year each. Data were obtained at baseline, and for forms of care at 6 and 12 months. The bar attachment over four implants provided greater retention of the prosthesis than the other forms of treatment in this study (39).

This research was carried out under a guided experimental simulation in order to test the retentive forces of three different types of attachment systems used mostly for overdentures assisted by implants. Nevertheless, the experimental design may have had a few drawbacks. The sample size of the experiment used was fairly small, but was comparable according to past studies (40). It should be noted that only mono-directional forces have been applied for the current in vitro study, which do not represent a practical model for a clinical case with overdentures $(41,42)$.

\section{REFERENCES}

1. Van Blarcom CW, Bello A, Eckert SE, Goodacre CJ, Morgano SM, Nathanson D. The Glossary of Prosthodontic Terms 8th edition. J Prosthet Dent. 2005; 94(1):10-92.

2. Kim Y. Attachment systems for mandibular implant overdentures: a systematic review. J Adv Prosthodont. 2012; 4: 197-203.

3. Thomason JM, Kelly SA, Bendkowski A, Ellis JS. Two implant retained overdentures - A review of the literature supporting the McGill and York consensus statements. J Dent. 2012; 40: 22-34. 
4. Spitzl C, Pröschel P, Wichmann M, Heckmann S. Longterm neuromuscular status in overdenture and complete denture patients with severe mandibular atrophy. Int J Oral Maxillofac Implants. 2012; 27: 155-61

5. Burns, D.R. Mandibular implant overdenture treatment: consensus and controversy. Journal of Prosthodontics 2000; 9: 37-46.

6. Sadowsky, S.J. Mandibular implant-retained overdenture: a literature review. Journal of Prosthetic Dentistry 2001; 86: 468-73.

7. Feine, J.S., Carlsson, G.E., Awad, M.A., Chehade, A., Duncan, W.J., et al. The McGill consensus statement on overdentures. Mandibular two-implant overdentures as first choice standard of care for edentulous patients. Montreal, Quebec, Int J Oral Maxillofac Implants 2002; 17 (4): 601-2.

8. Klemetti, E. Is there a certain number of implants needed to retain an overdenture? Journal of Oral Rehabilitation 2008; 35: 80-4.

9. British Society for the Study of Prosthetic Dentistry. The York consensus statement on implant-supported overdentures. Eur J Prosthodont Restor Dent 2009; 17 (4): 164-5.

10. Thomason, J.M., Feine, J., Exley, C., Moynihan, P., Mu“ ller, F., Naert, I., Ellis, J.S., Barclay, C., Butterworth, C., Scott, B., Lynch, C., Stewardson, D., Smith, P., Welfare, R., Hyde, P., McAndrew, R., Fenlon, M., Barclay, S. \& Barker, D. Mandibular two implant-supported overdenture as first choice standard of care for edentulous patients-the York Consensus Statement. British Dental Journal 2009; 207: 185-6.

11. Evtimovska E, Masri R, Driscoll CF, Romberg E. The change in retentive values of locator attachments and hader clips over time. J Prosthodont 2009; 18: 479-83.

12. Tahini G, Z.Baba N, Berberi A, Majzoub Z, Bassal H, Rifai K. Effect of Simulated Mastication on the Retention of Locator Attachments for Implant-Supported Overdentures: An InVitro Pilot Study. Journal of Prosthodontics 2020; 29: 74-9.

13. Hakan Bilhan, Onur Geckili, Tonguc Sulun, Tayfun Bilgin, A Quality-of-Life Comparison Between SelfAligning and Ball Attachment Systems for 2-ImplantRetained Mandibular Overdentures, J oral implantol. 2011; 37: 167-73.

14. Sadig W. A comparative in vitro study on the retention and stability of implant-supported over dentures. Quintessence Int. 2009; 40: 313-9.

15. Pasciuta M, Grossmann Y, Israel M. A prosthetic solution to restoring the edentulous mandible with limited inter-arch space using an implant-tissuesupported overdenture: A clinical report. J Prosthetic Dent. 2005; 93:116-20.

16. Naert I, Gizani S, Vuylsteke M, van Steenberghe D. A 5year randomized clinical trial on the influence of splinted and unsplinted oral implants in the mandibular overdenture therapy. Part I: Peri-implant outcome. Clin Oral Implants Res 1998; 9: 170-7.

17. Kleis WK, Kammer PW, Hartmann S, Al-Nawas B, Wagner W. A comparison of three different attachment systems for mandibular two implant overdentures: Oneyear report. Clin Imp Dent Res. 2010; 12: 209-18.
18. Ibrahim AM, Radi I AW. The effect of two types of attachments on the bone height changes around divergent implants retaining mandibular overdentures. Cairo Dent J. 2009; 25: 181-9.

19. Cordaro L, Di Torresanto VM, Petricevic N, Jornet PR, Torsello F. Single unit attachments improve peri-implant soft tissue conditions in mandibular overdentures supported by four implants. Clin Oral Impl Res. 2013; 24: 536-42.

20. Gulizio M, Agar J, Kelly R, Taylor T. Effect of implant angulation upon retention of over denture attachments. Int J Prosthodont. 2005; 14: 3-11

21. Kurian BP, D'lima J, Karthikeyan CR, Mathew J, Paul T, Hareesh MT. Prosthetic efficiency of implant-supported overdentures with locator attachment: A Clinical case report. J int oral health. 2015; 7: 129-32.

22. Theodoros T, Konstantinos M, Hiroshi H. Attachment systems for implant retained overdentures. J Impl Dent. 2006; 1: 24-34.

23. Doundoulakis JH, Eckert SE, Lindquist CC, Jeffcoat MK. The implant-supported overdenture as an alternative to the complete mandibular denture. J Am Dent Assoc 2003; 134: 1455-8.

24. Cune M, van Kampen P, van der Bilt A, Bosman F. Patient satisfaction and preference with magnet, bar-clip, and ball-socket retained mandibular implant overdentures: A cross-over clinical trial. Int $\mathrm{J}$ Prosthodont 2005; 18: 99-105.

25. Naert I, Gizani S, Vuylsteke M, Van Steenberghe D. A 5 -year prospective randomized clinical trial on the influence of splinted and unsplinted oral implants retaining a mandibular overdenture: Prosthetic aspects and patient satisfaction. J Oral Rehabil 1999; 26: 195-202.

26. Kobayashi M, Srinivasan M, Ammann P, Perriard J, Ohkubo C, Müller F, et al. Effects of in vitro cyclic dislodging on retentive force and removal torque of three overdenture attachment systems. Clin Oral Implants Res 2014; 25: 426-34

27. Shastry,T. , Anupama,N. M. , Shetty, S., Nalinakshamma, M. An in vitro comparative study to evaluate the retention of different attachment systems used in implant-retained overdentures. The Journal of Indian Prosthodontic Society 2016; 16 :159-166.

28. Sinclair PM, little RM. Maturation of untreated normal occlusions. Am J Orthod. 1983; 83: 114-23.

29. Georgiopoulos B, Kalioras K, Provatidis C, Manda M, Koidis P. The Effects of Implant Length and Diameter Prior to and After Osseointegration: A 2-D Finite Element Analysis. Journal of Oral Implantology. 2007; 33(5): 243-56.

30. Chung KH, Chung CY,Canga DR, Cronin RJ. Retention characteristics of attachment systems for implant overdentures. J Prosthodont 2004; 13: 221 -6.

31. Sarnat AE. The efficiency of cobalt samarium magnets as retentive units for overdentures. J Dent 1983; 11: 32433.

32. Scherer M, McGlumphy E, Seghi R, Campagni W. Comparison of Retention and Stability of ImplantRetained Overdentures Based upon Implant Number and Distribution. The International Journal of Oral \& Maxillofacial Implants. 2013; 28(6): 1619-28. 
33. Abdulamajeed A, H.Hassan R. The Effect of Implant Number, Distribution with Different Attachments on the Retention and Stability of Implant Supported Overdenture. Journal of Advanced Research in Medical and Health science. 2017; 3(9): 7-21.

34. Elmowafy DA, Emera RMK, Hegazy SA. Two versus three implants for retaining mandibular overdenture with low profile attachment: a study of retention and peri-implant tissue health. J Dent Maxillofacial Res. 2019; 2(4):70-77.

35. Batenburg, R.H., Raghoebar, G.M., Van Oort, R.P., Heijdenrijk, K. \& Boering, G. Mandibular overdentures supported by two or four endosteal implants. A prospective, comparative study. Journal of Oral and Maxillofacial Surgery 1998; 27: 435-9.

36. Meijer, H.J., Raghoebar, G.M., Batenburg, R.H., Visser, A. \& Vissink, A. Mandibular overdentures supported by two or four endosseous implants: a 10-year clinical trial. Clinical Oral Implant Research 2009; 20: 722-8.

37. Alsabeeha NH, Payne AG, Swain MV. Attachment systems for mandibular two-implant overdentures: A review of in vitro investigations on retention and wear features. Int J Prosthodont 2009; 22: 429-40.
38. Elsayd El, Dayekh M, Khalifa A. Locator Versus Bar Attachment Effect on the Retention and Stability of Implant-Retained Maxillary Overdenture An In Vitro Study. Journal of Prosthodontics 2019; 28: 627-36.

39. Burns, D.R., Unger, J.W., Coffey, J.P., Waldrop, T.C. \& Elswick, R.K. Jr Randomized, prospective, clinical evaluation of prosthodontic modalities for mandibular implant overdenture treatment. Journal of Prosthetic Dentistry 2011; 106: 12-22.

40. Kobayashi M, Srinivasan M, Ammann P, Perriard J, Ohkubo C, Müller F, et al. Effects of in vitro cyclic dislodging on retentive force and removal torque of three overdenture attachment systems. Clin Oral Implants Res 2014; 25: 426-34.

41. Steiner M, Ludwig K, Kern M. Retention forces of a new implant-supported bar attachment system. Clin Oral Implants Res 2009; 20: 1025-6.

42. Yang TC, Maeda Y, Gonda T, Kotecha S. Attachment systems for implant overdenture: Influence of implant inclination on retentive and lateral forces. Clin Oral Implants Res 2011; 22: 1315-9.

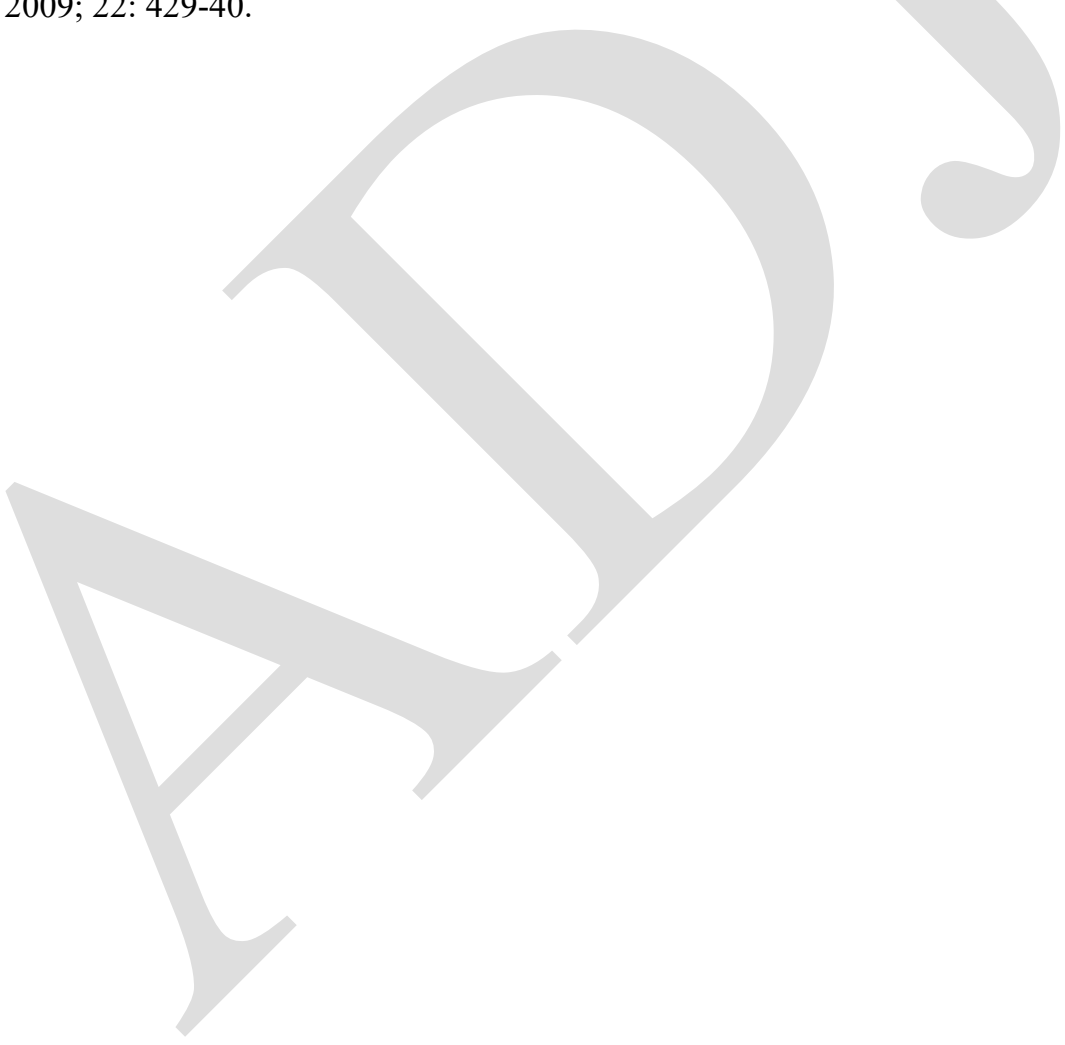

